\title{
Disease-modifying therapeutic directions for Lewy-Body dementias
}

\section{OPEN ACCESS}

Edited by:

Kevin J. O'Donovan,

United States Military Academy, USA

Reviewed by:

Alejandra Rojas Alvarez,

Pontificia Universidad Catolica

de Chile, Chile

Luke Esposito,

ProteoTech Inc, USA

*Correspondence:

Nandakumar S. Narayanan,

University of lowa, Pappajohn Biomedical Discovery Building - 1336,

169 Newton Road,

lowa City, IA 52242, USA

nandakumar-narayanan@uiowa.edu

${ }^{\dagger}$ These authors have contributed equally to this work.

Specialty section:

This article was submitted to

Neurodegeneration,

a section of the journal

Frontiers in Neuroscience

Received: 28 May 2015 Accepted: 04 August 2015

Published: 20 August 2015

Citation:

Zhang Q, Kim Y-C and Narayanan NS (2015) Disease-modifying therapeutic directions for Lewy-Body dementias.

Front. Neurosci. 9:293.

doi: 10.3389/fnins.2015.00293

\begin{abstract}
Qiang Zhang ${ }^{1,2 \dagger}$, Young-Cho Kim $^{1+}$ and Nandakumar S. Narayanan ${ }^{1,3 *}$
'Department of Neurology, University of lowa, lowa City, IA, USA, ${ }^{2}$ Physician Scientist Training Program, University of lowa, lowa City, IA, USA, ${ }^{3}$ Aging Mind and Brain Initiative, Carver College of Medicine, University of lowa, lowa City, IA, USA
\end{abstract}

Dementia with Lewy bodies (DLB) is the second leading cause of dementia following Alzheimer's disease (AD) and accounts for up to $25 \%$ of all dementia. DLB is distinct from $A D$ in that it involves extensive neuropsychiatric symptoms as well as motor symptoms, leads to enormous societal costs in terms of direct medical care and is associated with high financial and caregiver costs. Although, there are no disease-modifying therapies for DLB, we review several new therapeutic directions in treating DLB. We discuss progress in strategies to decrease the level of alpha-synuclein, to prevent the cell to cell transmission of misfolded alpha-synuclein, and the potential of brain stimulation in DLB.

Keywords: Dementia with Lewy Bodies, Parkinson's disease, Alzheimer's disease, Deep Brain Stimulation, disease-modifying therapy

\section{Introduction}

Dementia with Lewy bodies (DLB) is the second most common pathologic diagnosis of dementia, following Alzheimer's disease (AD), comprising 25\% of all dementias (Heidebrink, 2002; Mayo and Bordelon, 2014). Yet, DLB is underdiagnosed (Galvin and Balasubramaniam, 2013). The pathologic feature of DLB is the presence of Lewy bodies in the cortex and brainstem. Lewy-bodies are neuronal inclusions of abnormal filamentous assemblies of $\alpha$-synuclein and ubiquitin (Spillantini et al., 1998). DLB is associated with high burdens of neurofibrillary tangles (Merdes et al., 2003) but lower levels of amyloid- $\beta$ (Masliah et al., 2001).

DLB is characterized by fluctuating cognition and alertness, visual hallucinations, parkinsonian movement syndrome, REM sleep disorders, neuroleptic sensitivity, and reduced striatal dopamine. Due to the neuropsychiatric features of DLB, the costs for care of DLB patients is more than 2 times higher than AD patients (Bostrom et al., 2007; Ricci et al., 2009).

It is very difficult to distinguish DLB from dementia-associated with Parkinson's disease (PDD), which shares many underlying clinical and pathological features with DLB (Narayanan et al., 2013; Parker et al., 2013). Current guidelines arbitrarily distinguish DLB and PDD by the timing of onset of dementia in relation to motor symptoms (Lippa et al., 2007). One influential hypothesis is that synuclein spreads rostrally from the periphery (Braak et al., 2003). However, this hypothesis does not account for widespread cortical synuclein observed at initial diagnosis DLB.

Abbreviations: AD, Alzheimer's disease; BFCN, Basal forebrain cholinergic neurons; DBS, Deep brain stimulation; DLB, Dementia with Lewy bodies; NBM, nucleus basalis of Meynert; PDD, dementia-associated with Parkinson's disease; PD, Parkinson's disease; RNAi, RNA interference. 


\section{Targeting $\alpha$-synuclein}

The major component of Lewy bodies in DLB and Parkinson's disease (PD) is misfolded $\alpha$-synuclein (Spillantini et al., 1998). The normal $\alpha$-synuclein is a soluble protein and is involved in presynaptic processing of neurotransmitters, mitochondrial function and proteasome processing (Cheng et al., 2011). In DLB and PD, $\alpha$-synuclein aggregates in Lewy bodies and causes neuronal death. The $\alpha$-synuclein gene triplication and missense mutations, E46K and $\mathrm{A} 53 \mathrm{~T}$, are associated with familial PD/PDD/DLB. Overexpression of human wild-type $\alpha$ synuclein in mice leads to early cholinergic deficits and cognitive abnormalities, which appears before the development of motor deficits (Magen et al., 2012). Importantly, $\alpha$-synuclein knockout mice have normal neuroanatomy (Abeliovich et al., 2000), normal movement (Kokhan et al., 2012) and normal learning behavior (Chen et al., 2002). Therefore, various strategies have been employed to reduce $\alpha$-synuclein directly for the treatment of DLB and PD.

Nilotinib is an Abl tyrosine kinase inhibitor approved by FDA for the treatment of chronic myelogenous leukemia. Nilotinib decreased the level of $\alpha$-synuclein and reverse the loss of dopamine neurons in a mouse model overexpressing A35T mutant $\alpha$-synuclein (Hebron et al., 2013). It was also shown that the Abl inhibition through nilotinib promotes autophagic degradation of $\alpha$-synuclein. Another study has shown that $\alpha$-synuclein is a substrate of $\mathrm{Abl}$ and $\mathrm{Abl}$ directed phosphorylation leads to decreased $\alpha$-synuclein degradation through the autophagy and proteasome pathways (MahulMellier et al., 2014). A Phase I clinical trial of nilotinib is currently ongoing (http://clinicaltrials.gov/).

Secreted, extracellular $\alpha$-synuclein might play a crucial role in the passage of misfolded $\alpha$-synuclein from one cell to another (Lee et al., 2014). Therefore, immunotherapy targeting extracellular $\alpha$-synuclein has been proposed (Masliah et al., 2005, 2011; Valera and Masliah, 2013). Masliah et al. (2011) found that immunization with recombinant human $\alpha$-synuclein led to a reduction in $\alpha$-synuclein accumulation and neurodegeneration without neuroinflammation. With promising results from active immunization, they then applied passive immunization to the same mouse model using 9E4, an antibody targeting the C terminal epitopes of $\alpha$-synuclein. They found that 9E4 reduced the accumulation of $\alpha$-synuclein aggregates in neocortex and hippocampus. They also found that 9E4 treatment ameliorated motor behavior and learning deficits, and improved synaptic pathology. Bae et al. (2012) found that administration of anti$\alpha$-synuclein antibody into the brains of PGDF- $\alpha$-synuclein transgenic mice prevented cell-to-cell transmission of $\alpha$ synuclein. The antibodies aid in clearance of extracellular $\alpha$ synuclein proteins by microglia, thereby preventing their actions on neighboring cells. Misfolded extracellular $\alpha$-synuclein might interact with antibodies to form antigen-antibody complexes, and these complexes are endocytosed and transferred to the lysosomal compartment for degradation through autophagy (Masliah et al., 2011). Antibody bound extracellular $\alpha$-synuclein aggregates are also cleared by microglia cells (Bae et al., 2012). Tran et al. (2014) employed an antibody specific for misfolded $\alpha$-synuclein and obtained promising results in animal models as well. Recently, AFFiRiS AG, an Austria-based biotech company, developed a vaccine targeting $\mathrm{PD}$ and other synucleinopathies. The peptides used in the vaccine are designed to be too small to induce an $\alpha$-synuclein-specific $\mathrm{T}$ cell response, thus avoiding $\mathrm{T}$ cell autoimmunity (Mandler et al., 2014). The vaccine was tested in the PGDF- $\alpha$-synuclein and the Thy1- $\alpha$ synuclein transgenic mouse models. Active vaccination resulted in decreased accumulation of $\alpha$-synuclein oligomers in axons and synapses, reduced neurodegeneration, and improvements in motor and memory deficits in both models. Phase I clinical trials are currently ongoing in early PD and multiple-system atrophy patients with PD01A and PD03A vaccines (http://clinicaltrials. gov/).

Another strategy targeting $\alpha$-synuclein is RNA interference (RNAi) (Fire et al., 1998). Direct infusion of siRNA led to the reduction of $\alpha$-synuclein (Lewis et al., 2008; McCormack et al., 2010). Recent studies have employed virally-mediated RNAi delivery. Sapru et al. (2006) used lentivirus-mediated RNAi to successfully silence human $\alpha$-synuclein expression in the rat substantia nigra. Khodr et al. employed AAV-mediated RNAi, but found that this approach caused neurotoxicity (Han et al., 2011; Khodr et al., 2011, 2014). They then tried AAV-mediated RNAi embedded in mircoRNA30 backbone, and they were able to reverse $\alpha$-synuclein induced forelimb deficit and dopaminergic neuron loss. However, this approach induced inflammation. Transgene delivery using AAV was shown to be safe in previous studies and this technology has been used in human clinical trials in PD (LeWitt et al., 2011).

Other approaches employed to reduce $\alpha$-synuclein include ribozymes (Hayashita-Kinoh et al., 2006), intracellular expression of single chain antibodies (Zhou et al., 2004; Lynch et al., 2008; Yuan and Sierks, 2009), endogenous microRNA (Junn et al., 2009), and mirtrons (Sibley et al., 2012). A safe and effective approach to reduce the level of $\alpha$-synuclein will likely slow down or even reverse the progression of DLB.

\section{Targeting Synucleinopathy Progression}

$\alpha$-synuclein spreads via prion-like mechanisms (Angot et al., 2010). Initial evidence came from postmortem PD brains who received transplants of fetal mesencephalic neurons over 10 years before death. Two studies independently found Lewy bodies in grafted neurons (Kordower et al., 2008; Li et al., 2008). Further, studies in animal models have confirmed the prionlike spreading synucleinopathy (Desplats et al., 2009; Hansen et al., 2011; Kordower et al., 2011; Volpicelli-Daley et al., 2011; Angot et al., 2012; Luk et al., 2012a,b; Mougenot et al., 2012; Masuda-Suzukake et al., 2013; Rey et al., 2013; Sacino et al., 2013; Reyes et al., 2014). Interestingly, recent studies have shown that brain extracts from multiple-system atrophy and PD patients triggered $\alpha$-synuclein pathology in animal models (Watts et al., 2013; Recasens et al., 2014), in a way similar to the transmission of kuru disease to chimpanzees.

As shown in Figure 1, the development/progression of $\alpha$-synuclein pathology consists of the following steps: (1) 


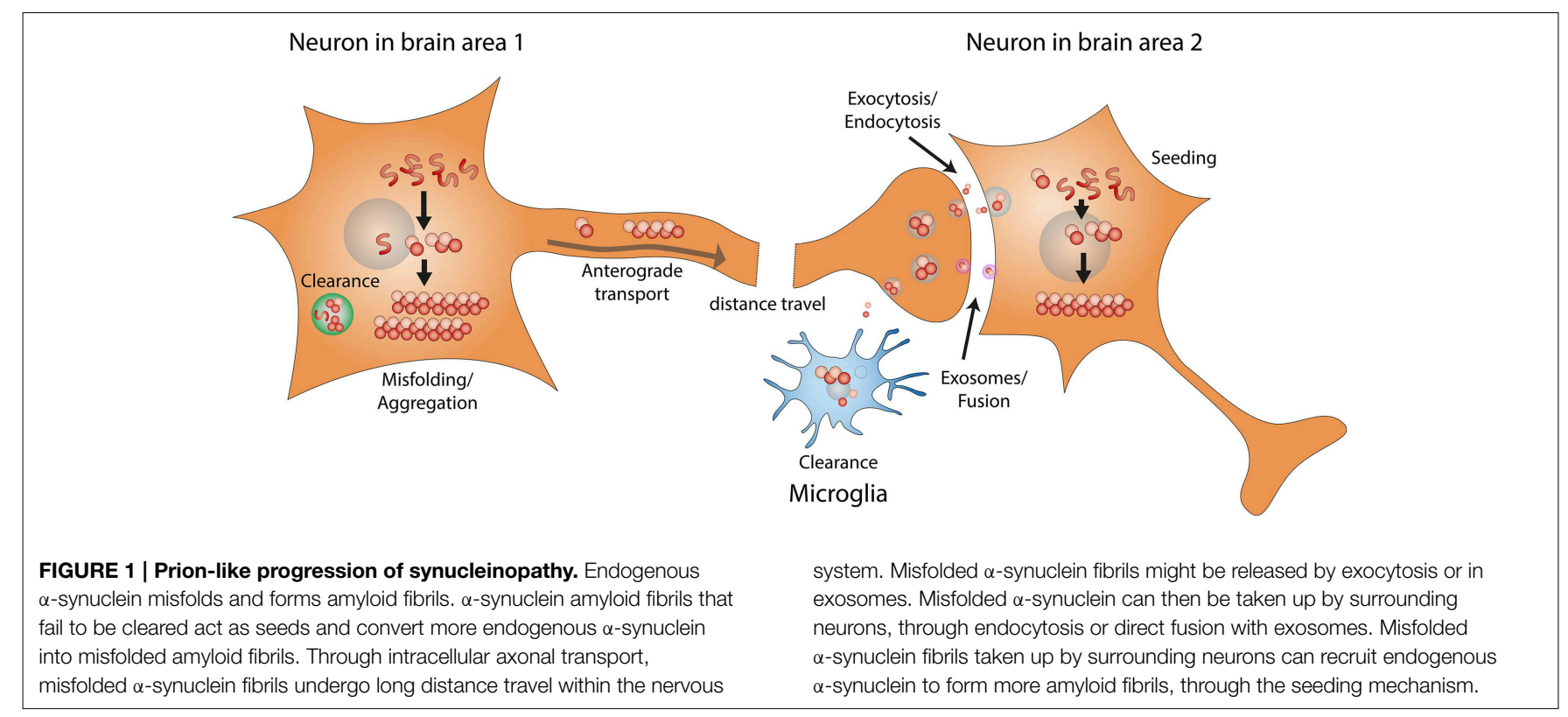

misfolding/aggregation of $\alpha$-synuclein, (2) induction of endogenous $\alpha$-synuclein to form more aggregates by the misfolded $\alpha$-synuclein aggregates (also known as "seeding"), (3) long distance transport of $\alpha$-synuclein aggregates, (4) secretion/exocytosis of $\alpha$-synuclein aggregates, (5) uptake/endocytosis of $\alpha$-synuclein aggregates by surrounding neurons, (6) formation of more $\alpha$-synuclein aggregates through "seeding" in the healthy neuron. Extensive studies have been performed to determine the details of each step, and potential therapeutic approaches are being developed to target the prion-like progression of synucleinopathy.

In vitro studies have shown that under certain conditions, recombinant $\alpha$-synuclein forms amyloid fibrils spontaneously (Narkiewicz et al., 2014). Addition of small amount (0.001\%) of preformed $\alpha$-synuclein fibrils to unfolded recombinant $\alpha$ synuclein solution could accelerate the formation of more fibrils, and this phenomenon is known as seeding (Wood et al., 1999). Strikingly, intrastriatal inoculation of recombinant $\alpha$ synuclein fibrils in wild type mice led to Lewy pathology in anatomically interconnected regions (Luk et al., 2012a). Agents preventing the formation of $\alpha$-synuclein fibrils or interfering with the seeding process could potentially serve as disease modifying treatments for both DLB and PDD. Efficient in vitro screening approaches and chronically $\alpha$ synuclein "infected" cell lines have been established (Herva et al., 2014; Narkiewicz et al., 2014). These should allow for highthroughput screening of compounds targeting synucleinopathy (Rochet, 2007). Several agents targeting $\alpha$-synuclein aggregation have been tested in cellular or animal models with promising results (El-Agnaf et al., 2004; Jiang et al., 2010; Zhou et al., 2011; Wagner et al., 2013). On the other hand, avoiding environmental exposure to agents associated with induction of synucleinopathy is very important (Elbaz et al., 2009).
It is well established that $\alpha$-synuclein is involved in vesicular trafficking and release (Burre et al., 2010; Nemani et al., 2010), and that it is transported along the axons (Jensen et al., 1999; George et al., 2013). Importantly, recent cell culture studies have utilized microfluidic chambers to separate neuronal cell bodies from their terminals, and demonstrated that $\alpha$ synuclein fibrils can be transported along the axons in both directions (Danzer et al., 2011; Volpicelli-Daley et al., 2011; Freundt et al., 2012). Freundt et al. (2012) used live-cell imaging and immunofluorescence, and confirmed the axonal transport of fluorescent $\alpha$-synuclein fibrils, and their transfer to second-order neurons through axon-to-soma transfer. In order to confirm the long distance transport of misfolded $\alpha$-synuclein in a synucleinopathy mouse model induced by intragastric administration of rotenone, Pan-Montojo et al. (2012) performed resection of the autonomic nerves and found that the progression of synucleinopathy was blocked. These results strongly indicate that the progression of synucleinopathy is based on the transneuronal and axonal transport of misfolded $\alpha$-synuclein.

A prerequisite of cell to cell transmission is the secretion and uptake of $\alpha$-synuclein fibrils. $\alpha$-synuclein is present in human plasma, cerebrospinal fluid, and brain interstitial fluid (Borghi et al., 2000; El-Agnaf et al., 2003; Emmanouilidou et al., 2011). $\alpha$-synuclein that is in the CSF and brain interstitial fluid is derived from CNS neurons (Mollenhauer et al., 2012), is present in cytoplasmic vesicles and could be secreted through exocytosis (Lee et al., 2005; Jang et al., 2010). Exocytosis of $\alpha$-synuclein and translocation of $\alpha$-synuclein into vesicles increases under various stress conditions (Jang et al., 2010). Intravesicular $\alpha$-synuclein was found to be more prone to aggregation and aggregated forms of $\alpha$-synuclein are also secreted from cells (Lee et al., 2005). Exocytosis of $\alpha$-synuclein was found to be independent of the ER-Golgi classical pathway, and exosome-associated exocytosis 
has been implicated in the release of misfolded $\alpha$-synuclein and the cell-to-cell transmission of synucleinopathy (Lee et al., 2005; Emmanouilidou et al., 2010). Exosome-associated exocytosis was thought to be directed by the multivesicular bodies-intraluminal vesicles mediated pathway (Emmanouilidou et al., 2010). In addition to exocytosis, the multivesicular bodies-intraluminal vesicles pathway also goes toward lysosomal degradation. It has been found that lysosomal dysfunction increases exosomeassociated $\alpha$-synuclein release and transmission (Alvarez-Erviti et al., 2011). Interestingly, Hasegawa et al. (2011) found that impaired biogenesis of multivesicular bodies was associated with hyper-secretion of $\alpha$-synuclein. $\alpha$-synuclein could also be released through the Rab11a-dependent recycling endosome pathway, and the blockage of multivesicular bodies mediated lysosomal degradation of $\alpha$-synuclein could have contributed to the hyper-secretion of $\alpha$-synuclein (Liu et al., 2009). Once released to the extracellular space, free misfolded $\alpha$-synuclein could get internalized by nearby neurons through endocytosis, and exosome-associated $\alpha$-synuclein could enter cytosol directly by fusion of the exosome with the plasma membrane (Desplats et al., 2009; Danzer et al., 2012). Immunotherapy approaches targeting extracellular $\alpha$-synuclein were discussed in the previous section. Strategies targeting the exocytosis and endocytosis processes are being considered, but these should be approached with caution, as severe side effects might ensue (Lee et al., 2014). In the meanwhile, other mechanisms have also been proposed for the pathogenesis of DLB: mitochondrial dysfunction, abnormal calcium handling, and altered inflammatory responses (Goedert et al., 2013; Mullin and Schapira, 2013; Overk and Masliah, 2014; Zaltieri et al., 2015). Also, it is important to note that some studies have provided evidences that argue against the concept of prion-like progression in synucleinopathy (Hallett et al., 2014).

\section{Deep Brain Stimulation}

In addition to $\alpha$-synuclein centered approaches, very recently, much attention has been attracted to another highly promising approach: Deep Brain Stimulation. Deep brain stimulation (DBS) has been approved by the FDA for the treatment of PD (Deuschl et al., 2006; Follett et al., 2010), essential tremor, dystonia, and obsessive-compulsive disorder (Rezai et al., 2008). It has been employed in research studies to treat chronic pain and major depressive disorder (Plow et al., 2012; Blumberger et al., 2013). Recently, DBS has been proposed in the treatment of cognitive disorders like AD (Sankar et al., 2014). Currently, two Phase I clinical studies are being conducted for the treatment of DLB with DBS targeting the nucleus basalis of Meynert (NBM) (http:// clinicaltrials.gov/). Here, we review DBS approaches that are directly and indirectly related to treating DLB.

DBS has the potential to modulate cognition. In PDD patient, Freund et al. (2009) and Barnikol et al. (2010) performed DBS targeting the NBM, a cholinergic nucleus. They found markedly improved cognition. This is the first and only published study targeting synucleinopathy associated dementia with DBS. This PDD patient received bilateral implantation of DBS leads into the STN and NBM. While isolated STN stimulation led to motor improvement without significant change in cognitive function, the addition of NBM stimulation is associated with improvement in cognitive functions. NBM stimulation also led to significant improvement in personality features, social communication, and overall quality of life. The authors believe that these effects were likely related to the effects of stimulating residual cholinergic projections and cell bodies in NBM. At this point, it is not clear whether DBS in NBM influences the progression of PDD or DLB, but two disease modifying mechanisms have been proposed based on preclinical studies. These include increased nerve growth factor (NGF) secretion and enhanced neurogenesis (Hotta et al., 2009; Jeong Da et al., 2014) (Figure 2). In terms of short term effects of NBM DBS, animal studies have indicated that NBM DBS is linked to brain plasticity and cortical map reorganization(Kilgard and Merzenich, 1998), and associated with enhanced learning and induction of immediate-early gene c-Fos (Boix-Trelis et al., 2006, 2009).

Basal forebrain cholinergic neurons (BFCN), consisting of NBM, medial septum and diagonal band of Broca, provide cholinergic innervations to the neocortex, entorhinal cortex and hippocampus. It has been found that NGF is very important for the survival and function of BFCN, and it has been shown that the majority of NGF nurturing BFCN comes from targeting areas of BFCN (neocortex, entorhinal cortex, and hippocampus) and is transported retrogradely through the axons back to the cell bodies of BFCN (Isacson et al., 2002). Interestingly, NBM DBS led to increased NGF secretion in wild type rats (Hotta et al., 2007, 2009), indicating that DBS could potentially reverse BFCN degeneration through increasing NGF trophic support. In another study, Jeong Da et al. (2014) injected 192 IgG-saporins intraventricularly to induce cholinergic lesion in rats. They found that DBS in the medial septum restores spatial memory in the setting of cholinergic neuron damage, and that this effect is

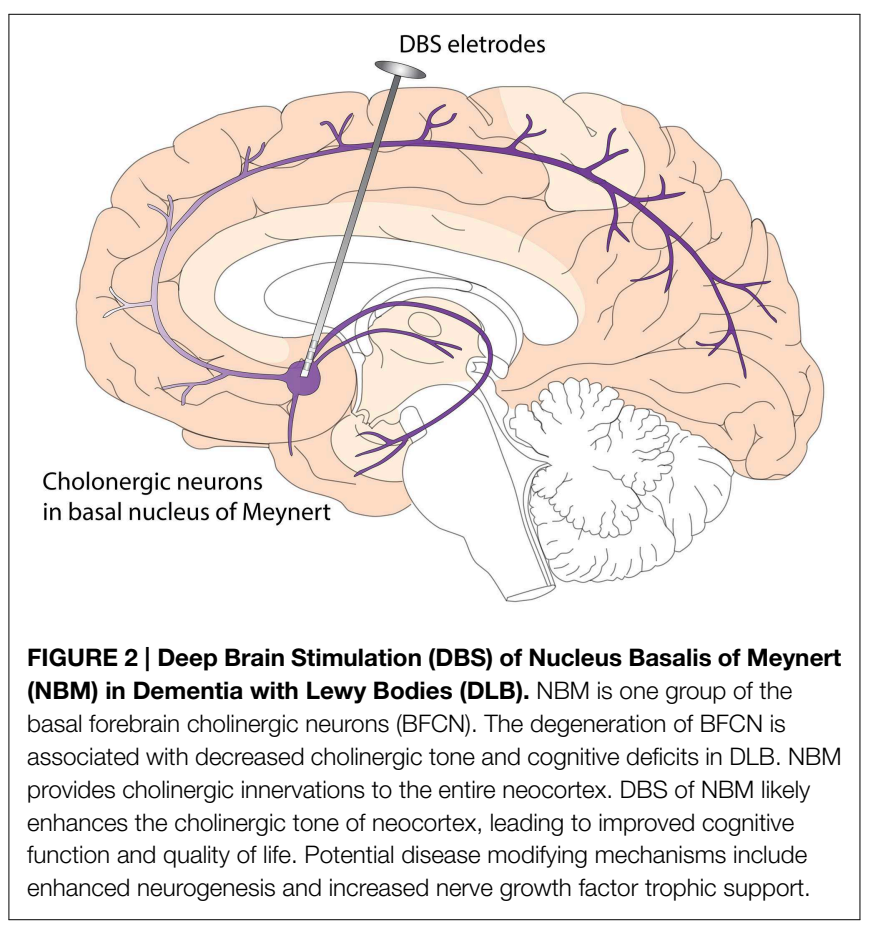


associated with an increase in hippocampal cholinergic activity and neurogenesis.

NBM DBS was first applied to an AD patient three decades ago (Turnbull et al., 1985). Turnbull et al. applied cyclic DBS to the left NBM for 9 months, and glucose utilization was relatively preserved in the left cerebral hemisphere of this AD patient. However, DBS did not lead to clinical improvement on memory or other cognitive measures. Recently, Kuhn et al. (2015) performed a Phase I clinical trial of NBM DBS on 6 mild to moderate AD patients. No safety concern was noted, and promising positive effects were observed on cognitive parameters including Alzheimer's Disease Assessment Scale-Cognitive subscale and Mini Mental Status Exam, global functioning as measured by Clinical Dementia Rating, subjectively perceived quality of life, and increased cortical glucose metabolism (via PET).

DBS targeting fornix, part of the Papez circuit which is very important in memory retention, has also been tested in $\mathrm{AD}$ patients, with promising results (Laxton et al., 2010). A Phase II clinical trial of Fornix DBS is currently underway in AD patients. Studies on human subjects have also indicated that DBS of entorhinal cortex (Suthana et al., 2012), anterior thalamic nucleus (Oh et al., 2012), pedunculopontine tegmental nucleus (Stefani et al., 2010), rhinal cortex and hippocampus (Fell et al., 2013) might also enhance memory and cognitive functions. Animal studies with DBS targeting fornix (Hescham et al., 2013), entorhinal cortex (Stone et al., 2011), anterior thalamic nucleus (Hamani et al., 2011; Chen et al., 2014) and hippocampus (Berger et al., 2011) have also indicated positive effects on memory and cognitive functions.

Animal studies have targeted other areas of the brain and evaluated the effects of DBS on cognitive functions (Hardenacke et al., 2013). Promising results were obtained through DBS targeting anterior caudate nucleus (Williams and Eskandar, 2006), midline thalamic nuclei (Arrieta-Cruz et al., 2010), central thalamus (Shirvalkar et al., 2006; Mair and Hembrook, 2008; Shah et al., 2009; Smith et al., 2009), lateral hypothalamus (Soriano-Mas et al., 2005, 2007; Ruiz-Medina et al., 2008a,b; Huguet et al., 2009; Aldavert-Vera et al., 2013), and amygdala (Kadar et al., 2011).

\section{References}

Abeliovich, A., Schmitz, Y., Farinas, I., Choi-Lundberg, D., Ho, W. H., Castillo, P. E., et al. (2000). Mice lacking alpha-synuclein display functional deficits in the nigrostriatal dopamine system. Neuron 25, 239-252. doi: 10.1016/S08966273(00)80886-7

Aldavert-Vera, L., Huguet, G., Costa-Miserachs, D., Ortiz, S. P., Kádár, E., Morgado-Bernal, I., et al. (2013). Intracranial self-stimulation facilitates activeavoidance retention and induces expression of c-Fos and Nurrl in rat brain memory systems. Behav. Brain Res. 250, 46-57. doi: 10.1016/j.bbr.2013. 04.025

Alvarez-Erviti, L., Seow, Y., Schapira, A. H., Gardiner, C., Sargent, I. L., Wood, M. J., et al. (2011). Lysosomal dysfunction increases exosome-mediated alpha-synuclein release and transmission. Neurobiol. Dis. 42, 360-367. doi: 10.1016/j.nbd.2011.01.029

Angot, E., Steiner, J. A., Hansen, C., Li, J. Y., and Brundin, P. (2010). Are synucleinopathies prion-like disorders? Lancet Neurol. 9, 1128-1138. doi: 10.1016/S1474-4422(10)70213-1
Given its low complication rate and reversibility (Deuschl et al., 2006; Voges et al., 2006), DBS seems to be a safe and promising approach in DLB management. Though long term disease modifying profile is not clear at this point, DBS will likely improve short term cognitive functions, and importantly, the quality of life of patients with DLB and PDD (Freund et al., 2009). Though DBS targeting fornix has attracted much attention in the field of AD treatment, NBM DBS currently holds the most promise for DLB patients. Unlike AD, which usually presents with memory deficits, DLB usually presents with fluctuating cognition and visuospatial deficits with relative sparing of memory in earlier stages (Mayo and Bordelon, 2014). While waiting for the results of ongoing clinical trials, it is worth noting that no DBS studies have been performed on animal models of dementia associated with synucleinopathy. These preclinical studies will likely accelerate and validate clinical application of DBS in DLB and other synucleinopathy associated dementia.

\section{Conclusion}

DLB is the second leading cause of dementia following AD, and disease modifying therapies are urgently needed. Significant progress has been made in the past decade regarding the underlying mechanism of DLB pathogenesis. Future therapies might modify the progression of DLB by targeting $\alpha$-synuclein or by stimulating deep brain structures. Cutting edge research into the basic mechanism of DLB pathogenesis and preclinical studies testing novel therapies will continue to play crucial roles in the development of disease modifying treatments for DLB.

\section{Acknowledgments}

QZ is supported by the Physician Scientist Training Program (PSTP) at Carver College of Medicine, University of Iowa. YK is supported by the NARSAD Young Investigator Award. NN is currently funded by the US National Institutes of Health (K08 NS078100, R01 NS089470).

Angot, E., Steiner, J. A., Lema Tomé, C. M., Ekström, P., Mattsson, B., Björklund, A., et al. (2012). Alpha-synuclein cell-to-cell transfer and seeding in grafted dopaminergic neurons in vivo. PLoS ONE 7:e39465. doi: 10.1371/journal.pone.0039465

Arrieta-Cruz, I., Pavlides, C., and Pasinetti, G. M. (2010). Deep brain stimulation in midline thalamic region facilitates synaptic transmission and shortterm memory in a mouse model of Alzheimer's Disease. Transl. Neurosci. 1, 188-194. doi: 10.2478/v10134-010-0023-x

Bae, E. J., Lee, H. J., Rockenstein, E., Ho, D. H., Park, E. B., Yang, N. Y., et al. (2012). Antibody-aided clearance of extracellular alpha-synuclein prevents cell-to-cell aggregate transmission. J. Neurosci. 32, 13454-13469. doi: 10.1523/JNEUROSCI.1292-12.2012

Barnikol, T. T., Pawelczyk, N. B., Barnikol, U. B., Kuhn, J., Lenartz, D., Sturm, V., et al. (2010). Changes in apraxia after deep brain stimulation of the nucleus basalis Meynert in a patient with Parkinson dementia syndrome. Mov. Disord. 25, 1519-1520. doi: $10.1002 / \mathrm{mds} .23141$

Berger, T. W., Hampson, R. E., Song, D., Goonawardena, A., Marmarelis, V. Z., and Deadwyler, S. A. (2011). A cortical neural prosthesis for 
restoring and enhancing memory. J. Neural Eng. 8:046017. doi: 10.1088/17412560/8/4/046017

Blumberger, D. M., Mulsant, B. H., and Daskalakis, Z. J. (2013). What is the role of brain stimulation therapies in the treatment of depression? Curr. Psychiatry Rep. 15, 368. doi: 10.1007/s11920-013-0368-1

Boix-Trelis, N., Vale-Martínez, A., Guillazo-Blanch, G., Costa-Miserachs, D., and Martí-Nicolovius, M. (2006). Effects of nucleus basalis magnocellularis stimulation on a socially transmitted food preference and c-Fos expression. Learn. Mem. 13, 783-793. doi: 10.1101/lm.305306

Boix-Trelis, N., Vale-Martinez, A., Guillazo-Blanch, G., and Marti-Nicolovius, M. (2009). Induction of c-Fos expression by electrical stimulation of the nucleus basalis magnocellularis. Neurosci. Lett. 449, 137-141. doi: 10.1016/j.neulet.2008.10.105

Borghi, R., Marchese, R., Negro, A., Marinelli, L., Forloni, G., Zaccheo, D., et al. (2000). Full length alpha-synuclein is present in cerebrospinal fluid from Parkinson's disease and normal subjects. Neurosci. Lett. 287, 65-67. doi: 10.1016/S0304-3940(00)01153-8

Boström, F., Jönsson, L., Minthon, L., and Londos, E. (2007). Patients with Lewy body dementia use more resources than those with Alzheimer's disease. Int. J. Geriatr. Psychiatry 22, 713-719. doi: 10.1002/gps.1738

Braak, H., Del Tredici, K., Rub, U., De Vos, R. A., Jansen Steur, E. N., and Braak, E. (2003). Staging of brain pathology related to sporadic Parkinson's disease. Neurobiol. Aging 24, 197-211. doi: 10.1016/S0197-4580(02)00065-9

Burre, J., Sharma, M., Tsetsenis, T., Buchman, V., Etherton, M. R., and Sudhof, T. C. (2010). Alpha-synuclein promotes SNARE-complex assembly in vivo and in vitro. Science 329, 1663-1667. doi: 10.1126/science.1195227

Chen, N., Dong, S., Yan, T., Yan, N., Ma, Y., and Yu, C. (2014). High-frequency stimulation of anterior nucleus thalamus improves impaired cognitive function induced by intra-hippocampal injection of Abeta1-40 in rats. Chin. Med. J. 127, 125-129. doi: 10.3760/cma.j.issn.0366-6999.20131025

Chen, P. E., Specht, C. G., Morris, R. G., and Schoepfer, R. (2002). Spatial learning is unimpaired in mice containing a deletion of the alpha-synuclein locus. Eur. J. Neurosci. 16, 154-158. doi: 10.1046/j.1460-9568.2002.02062.x

Cheng, F., Vivacqua, G., and Yu, S. (2011). The role of alpha-synuclein in neurotransmission and synaptic plasticity. J. Chem. Neuroanat. 42, 242-248. doi: 10.1016/j.jchemneu.2010.12.001

Danzer, K. M., Kranich, L. R., Ruf, W. P., Cagsal-Getkin, O., Winslow, A. R., Zhu, L., et al. (2012). Exosomal cell-to-cell transmission of alpha synuclein oligomers. Mol. Neurodegener. 7:42. doi: 10.1186/1750-1326-7-42

Danzer, K. M., Ruf, W. P., Putcha, P., Joyner, D., Hashimoto, T., Glabe, C., et al. (2011). Heat-shock protein 70 modulates toxic extracellular alpha-synuclein oligomers and rescues trans-synaptic toxicity. FASEB J. 25, 326-336. doi: 10.1096/fj.10-164624

Desplats, P., Lee, H. J., Bae, E. J., Patrick, C., Rockenstein, E., Crews, L., et al. (2009). Inclusion formation and neuronal cell death through neuron-to-neuron transmission of alpha-synuclein. Proc. Natl. Acad. Sci. U.S.A. 106, 13010-13015. doi: 10.1073/pnas.0903691106

Deuschl, G., Schade-Brittinger, C., Krack, P., Volkmann, J., Schäfer, H., Bötzel, K., et al. (2006). A randomized trial of deep-brain stimulation for Parkinson's disease. N. Engl. J. Med. 355, 896-908. doi: 10.1056/ NEJMoa060281

El-Agnaf, O. M., Paleologou, K. E., Greer, B., Abogrein, A. M., King, J. E., Salem, S. A., et al. (2004). A strategy for designing inhibitors of alpha-synuclein aggregation and toxicity as a novel treatment for Parkinson's disease and related disorders. FASEB J. 18, 1315-1317. doi: 10.1096/fj.03-1346fje

El-Agnaf, O. M., Salem, S. A., Paleologou, K. E., Cooper, L. J., Fullwood, N. J., Gibson, M. J., et al. (2003). Alpha-synuclein implicated in Parkinson's disease is present in extracellular biological fluids, including human plasma. FASEB J. 17, 1945-1947. doi: 10.1096/fj.03-0098fje

Elbaz, A., Clavel, J., Rathouz, P. J., Moisan, F., Galanaud, J. P., Delemotte, B., et al. (2009). Professional exposure to pesticides and Parkinson disease. Ann. Neurol. 66, 494-504. doi: 10.1002/ana.21717

Emmanouilidou, E., Elenis, D., Papasilekas, T., Stranjalis, G., Gerozissis, K., Ioannou, P. C., et al. (2011). Assessment of alpha-synuclein secretion in mouse and human brain parenchyma. PLoS ONE 6:e22225. doi: 10.1371/journal.pone.0022225

Emmanouilidou, E., Melachroinou, K., Roumeliotis, T., Garbis, S. D., Ntzouni, M., Margaritis, L. H., et al. (2010). Cell-produced alpha-synuclein is secreted in a calcium-dependent manner by exosomes and impacts neuronal survival. J. Neurosci. 30, 6838-6851. doi: 10.1523/JNEUROSCI.5699-09.2010

Fell, J., Staresina, B. P., Do Lam, A. T., Widman, G., Helmstaedter, C., Elger, C. E., et al. (2013). Memory modulation by weak synchronous deep brain stimulation: a pilot study. Brain Stimul. 6, 270-273. doi: 10.1016/j.brs.2012.08.001

Fire, A., Xu, S., Montgomery, M. K., Kostas, S. A., Driver, S. E., and Mello, C. C. (1998). Potent and specific genetic interference by double-stranded RNA in Caenorhabditis elegans. Nature 391, 806-811.

Follett, K. A., Weaver, F. M., Stern, M., Hur, K., Harris, C. L., Luo, P., et al. (2010). Pallidal versus subthalamic deep-brain stimulation for Parkinson's disease. $N$. Engl. J. Med. 362, 2077-2091. doi: 10.1056/NEJMoa0907083

Freund, H. J., Kuhn, J., Lenartz, D., Mai, J. K., Schnell, T., Klosterkoetter, J., et al. (2009). Cognitive functions in a patient with Parkinson-dementia syndrome undergoing deep brain stimulation. Arch. Neurol. 66, 781-785. doi: 10.1001/archneurol.2009.102

Freundt, E. C., Maynard, N., Clancy, E. K., Roy, S., Bousset, L., Sourigues, Y., et al. (2012). Neuron-to-neuron transmission of alpha-synuclein fibrils through axonal transport. Ann. Neurol. 72, 517-524. doi: 10.1002/ana.23747

Galvin, J. E., and Balasubramaniam, M. (2013). Lewy body dementia: the underrecognized but common FOE. Cerebrum 2013, 13.

George, S., Rey, N. L., Reichenbach, N., Steiner, J. A., and Brundin, P. (2013). alpha-Synuclein: the long distance runner. Brain Pathol. 23, 350-357. doi: 10.1111/bpa.12046

Goedert, M., Spillantini, M. G., Del Tredici, K., and Braak, H. (2013). 100 years of Lewy pathology. Nat. Rev. Neurol. 9, 13-24. doi: 10.1038/nrneurol.2012.242

Hallett, P. J., Cooper, O., Sadi, D., Robertson, H., Mendez, I., and Isacson, O. (2014). Long-term health of dopaminergic neuron transplants in Parkinson's disease patients. Cell Rep. 7, 1755-1761. doi: 10.1016/j.celrep.2014.05.027

Hamani, C., Stone, S. S., Garten, A., Lozano, A. M., and Winocur, G. (2011). Memory rescue and enhanced neurogenesis following electrical stimulation of the anterior thalamus in rats treated with corticosterone. Exp. Neurol. 232, 100-104. doi: 10.1016/j.expneurol.2011.08.023

Han, Y., Khodr, C. E., Sapru, M. K., Pedapati, J., and Bohn, M. C. (2011). A microRNA embedded AAV alpha-synuclein gene silencing vector for dopaminergic neurons. Brain Res. 1386, 15-24. doi: 10.1016/j.brainres.2011.02.041

Hansen, C., Angot, E., Bergström, A. L., Steiner, J. A., Pieri, L., Paul, G., et al. (2011). alpha-Synuclein propagates from mouse brain to grafted dopaminergic neurons and seeds aggregation in cultured human cells. J. Clin. Invest. 121, 715-725. doi: 10.1172/JCI43366

Hardenacke, K., Shubina, E., Buhrle, C. P., Zapf, A., Lenartz, D., Klosterkötter J., et al. (2013). Deep brain stimulation as a tool for improving cognitive functioning in Alzheimer's dementia: a systematic review. Front. Psychiatry 4:159. doi: 10.3389/fpsyt.2013.00159

Hasegawa, T., Konno, M., Baba, T., Sugeno, N., Kikuchi, A., Kobayashi, M., et al. (2011). The AAA-ATPase VPS4 regulates extracellular secretion and lysosomal targeting of alpha-synuclein. PLoS ONE 6:e29460. doi: 10.1371/journal.pone.0029460

Hayashita-Kinoh, H., Yamada, M., Yokota, T., Mizuno, Y., and Mochizuki, H. (2006). Down-regulation of alpha-synuclein expression can rescue dopaminergic cells from cell death in the substantia nigra of Parkinson's disease rat model. Biochem. Biophys. Res. Commun. 341, 1088-1095. doi: 10.1016/j.bbrc.2006.01.057

Hebron, M. L., Lonskaya, I., and Moussa, C. E. (2013). Nilotinib reverses loss of dopamine neurons and improves motor behavior via autophagic degradation of alpha-synuclein in Parkinson's disease models. Hum. Mol. Genet. 22, 3315-3328. doi: $10.1093 / \mathrm{hmg} / \mathrm{ddt} 192$

Heidebrink, J. L. (2002). Is dementia with Lewy bodies the second most common cause of dementia? J. Geriatr. Psychiatry Neurol. 15, 182-187. doi: 10.1177/089198870201500402

Herva, M. E., Zibaee, S., Fraser, G., Barker, R. A., Goedert, M., and Spillantini, M. G. (2014). Anti-amyloid compounds inhibit alpha-synuclein aggregation induced by protein misfolding cyclic amplification (PMCA). J. Biol. Chem. 289, 11897-11905. doi: 10.1074/jbc.M113.542340

Hescham, S., Lim, L. W., Jahanshahi, A., Steinbusch, H. W., Prickaerts, J., Blokland, A., et al. (2013). Deep brain stimulation of the forniceal area enhances memory functions in experimental dementia: the role of stimulation parameters. Brain Stimul. 6, 72-77. doi: 10.1016/j.brs.2012.01.008 
Hotta, H., Kagitani, F., Kondo, M., and Uchida, S. (2009). Basal forebrain stimulation induces NGF secretion in ipsilateral parietal cortex via nicotinic receptor activation in adult, but not aged rats. Neurosci. Res. 63, 122-128. doi: 10.1016/j.neures.2008.11.004

Hotta, H., Uchida, S., and Kagitani, F. (2007). Stimulation of the nucleus basalis of Meynert produces an increase in the extracellular release of nerve growth factor in the rat cerebral cortex. J. Physiol. Sci. 57, 383-387. doi: 10.2170/physiolsci.SC008107

Huguet, G., Aldavert-Vera, L., Kádár, E., Peña De Ortiz, S., MorgadoBernal, I., and Segura-Torres, P. (2009). Intracranial self-stimulation to the lateral hypothalamus, a memory improving treatment, results in hippocampal changes in gene expression. Neuroscience 162, 359-374. doi: 10.1016/j.neuroscience.2009.04.074

Isacson, O., Seo, H., Lin, L., Albeck, D., and Granholm, A. C. (2002). Alzheimer's disease and Down's syndrome: roles of APP, trophic factors and ACh. Trends Neurosci. 25, 79-84. doi: 10.1016/S0166-2236(02)02037-4

Jang, A., Lee, H. J., Suk, J. E., Jung, J. W., Kim, K. P., and Lee, S. J. (2010). Non-classical exocytosis of alpha-synuclein is sensitive to folding states and promoted under stress conditions. J. Neurochem. 113, 1263-1274. doi: 10.1111/j.1471-4159.2010.06695.x

Jensen, P. H., Li, J. Y., Dahlström, A., and Dotti, C. G. (1999). Axonal transport of synucleins is mediated by all rate components. Eur. J. Neurosci. 11, 3369-3376.

Jeong Da, U., Lee, J. E., Lee, S. E., Chang, W. S., Kim, S. J., and Chang, J. W. (2014). Improvements in memory after medial septum stimulation are associated with changes in hippocampal cholinergic activity and neurogenesis. Biomed. Res. Int. 2014:568587. doi: 10.1155/2014/568587

Jiang, M., Porat-Shliom, Y., Pei, Z., Cheng, Y., Xiang, L., Sommers, K., et al. (2010). Baicalein reduces $\mathrm{E} 46 \mathrm{~K}$ alpha-synuclein aggregation in vitro and protects cells against E46K alpha-synuclein toxicity in cell models of familiar Parkinsonism. J. Neurochem. 114, 419-429. doi: 10.1111/j.1471-4159.2010.06752.x

Junn, E., Lee, K. W., Jeong, B. S., Chan, T. W., Im, J. Y., and Mouradian, M. M. (2009). Repression of alpha-synuclein expression and toxicity by microRNA-7. Proc. Natl. Acad. Sci. U.S.A. 106, 13052-13057. doi: 10.1073/pnas.0906277106

Kadar, E., Aldavert-Vera, L., Huguet, G., Costa-Miserachs, D., Morgado-Bernal, I., and Segura-Torres, P. (2011). Intracranial self-stimulation induces expression of learning and memory-related genes in rat amygdala. Genes Brain Behav. 10, 69-77. doi: 10.1111/j.1601-183X.2010.00609.x

Khodr, C. E., Becerra, A., Han, Y., and Bohn, M. C. (2014). Targeting alpha-synuclein with a microRNA-embedded silencing vector in the rat substantia nigra: positive and negative effects. Brain Res. 1550, 47-60. doi: 10.1016/j.brainres.2014.01.010

Khodr, C. E., Sapru, M. K., Pedapati, J., Han, Y., West, N. C., Kells, A. P., et al. (2011). An alpha-synuclein AAV gene silencing vector ameliorates a behavioral deficit in a rat model of Parkinson's disease, but displays toxicity in dopamine neurons. Brain Res. 1395, 94-107. doi: 10.1016/j.brainres.2011.04.036

Kilgard, M. P., and Merzenich, M. M. (1998). Cortical map reorganization enabled by nucleus basalis activity. Science 279, 1714-1718

Kokhan, V. S., Afanasyeva, M. A., and Van'kin, G. I. (2012). Alpha-Synuclein knockout mice have cognitive impairments. Behav. Brain Res. 231, 226-230. doi: 10.1016/j.bbr.2012.03.026

Kordower, J. H., Chu, Y., Hauser, R. A., Freeman, T. B., and Olanow, C. W. (2008). Lewy body-like pathology in long-term embryonic nigral transplants in Parkinson's disease. Nat. Med. 14, 504-506. doi: 10.1038/nm1747

Kordower, J. H., Dodiya, H. B., Kordower, A. M., Terpstra, B., Paumier, K., Madhavan, L., et al. (2011). Transfer of host-derived alpha synuclein to grafted dopaminergic neurons in rat. Neurobiol. Dis. 43, 552-557. doi: 10.1016/j.nbd.2011.05.001

Kuhn, J., Hardenacke, K., Lenartz, D., Gruendler, T., Ullsperger, M., Bartsch, C., et al. (2015). Deep brain stimulation of the nucleus basalis of Meynert in Alzheimer's dementia. Mol. Psychiatry 20, 353-360. doi: 10.1038/mp.2014.32

Laxton, A. W., Tang-Wai, D. F., McAndrews, M. P., Zumsteg, D., Wennberg, R., Keren, R., et al. (2010). A phase I trial of deep brain stimulation of memory circuits in Alzheimer's disease. Ann. Neurol. 68, 521-534. doi: 10.1002/ana.22089

Lee, H. J., Bae, E. J., and Lee, S. J. (2014). Extracellular alpha-synuclein-a novel and crucial factor in Lewy body diseases. Nat. Rev. Neurol. 10, 92-98. doi: 10.1038/nrneurol.2013.275
Lee, H. J., Patel, S., and Lee, S. J. (2005). Intravesicular localization and exocytosis of alpha-synuclein and its aggregates. J. Neurosci. 25, 6016-6024. doi: 10.1523/JNEUROSCI.0692-05.2005

Lewis, J., Melrose, H., Bumcrot, D., Hope, A., Zehr, C., Lincoln, S., et al. (2008). In vivo silencing of alpha-synuclein using naked siRNA. Mol. Neurodegener. 3:19. doi: 10.1186/1750-1326-3-19

LeWitt, P. A., Rezai, A. R., Leehey, M. A., Ojemann, S. G., Flaherty, A. W., Eskandar, E. N., et al. (2011). AAV2-GAD gene therapy for advanced Parkinson's disease: a double-blind, sham-surgery controlled, randomised trial. Lancet Neurol. 10, 309-319. doi: 10.1016/S1474-4422(11)70039-4

Li, J. Y., Englund, E., Holton, J. L., Soulet, D., Hagell, P., Lees, A. J., et al. (2008). Lewy bodies in grafted neurons in subjects with Parkinson's disease suggest host-to-graft disease propagation. Nat. Med. 14, 501-503. doi: 10.1038/nm1746

Lippa, C. F., Duda, J. E., Grossman, M., Hurtig, H. I., Aarsland, D., Boeve, B. F., et al. (2007). DLB and PDD boundary issues: diagnosis, treatment, molecular pathology, and biomarkers. Neurology 68, 812-819. doi: 10.1212/01.wnl.0000256715.13907.d3

Liu, J., Zhang, J. P., Shi, M., Quinn, T., Bradner, J., Beyer, R., et al. (2009). Rab1la and HSP90 regulate recycling of extracellular alpha-synuclein. J. Neurosci. 29, 1480-1485. doi: 10.1523/JNEUROSCI.6202-08.2009

Luk, K. C., Kehm, V., Carroll, J., Zhang, B., O'brien, P., Trojanowski, J. Q., et al. (2012a). Pathological alpha-synuclein transmission initiates Parkinsonlike neurodegeneration in nontransgenic mice. Science 338, 949-953. doi: $10.1126 /$ science. 1227157

Luk, K. C., Kehm, V. M., Zhang, B., O'brien, P., Trojanowski, J. Q., and Lee, V. M. (2012b). Intracerebral inoculation of pathological alpha-synuclein initiates a rapidly progressive neurodegenerative alpha-synucleinopathy in mice. J. Exp. Med. 209, 975-986. doi: 10.1084/jem.20112457

Lynch, S. M., Zhou, C., and Messer, A. (2008). An scFv intrabody against the nonamyloid component of alpha-synuclein reduces intracellular aggregation and toxicity. J. Mol. Biol. 377, 136-147. doi: 10.1016/j.jmb.2007.11.096

Magen, I., Fleming, S. M., Zhu, C., Garcia, E. C., Cardiff, K. M., Dinh, D., et al. (2012). Cognitive deficits in a mouse model of pre-manifest Parkinson's disease. Eur. J. Neurosci. 35, 870-882. doi: 10.1111/j.1460-9568.2012.08012.x

Mahul-Mellier, A. L., Fauvet, B., Gysbers, A., Dikiy, I., Oueslati, A., Georgeon, S., et al. (2014). c-Abl phosphorylates alpha-synuclein and regulates its degradation: implication for alpha-synuclein clearance and contribution to the pathogenesis of Parkinson's disease. Hum. Mol. Genet. 23, 2858-2879. doi: $10.1093 / \mathrm{hmg} / \mathrm{ddt} 674$

Mair, R. G., and Hembrook, J. R. (2008). Memory enhancement with eventrelated stimulation of the rostral intralaminar thalamic nuclei. J. Neurosci. 28 , 14293-14300. doi: 10.1523/JNEUROSCI.3301-08.2008

Mandler, M., Valera, E., Rockenstein, E., Weninger, H., Patrick, C., Adame, A., et al. (2014). Next-generation active immunization approach for synucleinopathies: implications for Parkinson's disease clinical trials. Acta Neuropathol. 127, 861-879. doi: 10.1007/s00401-014-1256-4

Masliah, E., Rockenstein, E., Adame, A., Alford, M., Crews, L., Hashimoto, M. et al. (2005). Effects of alpha-synuclein immunization in a mouse model of Parkinson's disease. Neuron 46, 857-868. doi: 10.1016/j.neuron.2005.05.010

Masliah, E., Rockenstein, E., Mante, M., Crews, L., Spencer, B., Adame, A., et al. (2011). Passive immunization reduces behavioral and neuropathological deficits in an alpha-synuclein transgenic model of Lewy body disease. PLoS ONE 6:e19338. doi: 10.1371/journal.pone.0019338

Masliah, E., Rockenstein, E., Veinbergs, I., Sagara, Y., Mallory, M., Hashimoto, M., et al. (2001). beta-amyloid peptides enhance alpha-synuclein accumulation and neuronal deficits in a transgenic mouse model linking Alzheimer's disease and Parkinson's disease. Proc. Natl. Acad. Sci. U.S.A. 98, 12245-12250. doi: $10.1073 /$ pnas.211412398

Masuda-Suzukake, M., Nonaka, T., Hosokawa, M., Oikawa, T., Arai, T., Akiyama, H., et al. (2013). Prion-like spreading of pathological alpha-synuclein in brain. Brain 136, 1128-1138. doi: 10.1093/brain/awt037

Mayo, M. C., and Bordelon, Y. (2014). Dementia with Lewy bodies. Semin. Neurol. 34, 182-188. doi: $10.1055 / \mathrm{s}-0034-1381741$

McCormack, A. L., Mak, S. K., Henderson, J. M., Bumcrot, D., Farrer, M. J., and Di Monte, D. A. (2010). Alpha-synuclein suppression by targeted small interfering RNA in the primate substantia nigra. PLOS ONE 5:e12122. doi: 10.1371/journal.pone.0012122 
Merdes, A. R., Hansen, L. A., Jeste, D. V., Galasko, D., Hofstetter, C. R., Ho, G. J., et al. (2003). Influence of Alzheimer pathology on clinical diagnostic accuracy in dementia with Lewy bodies. Neurology 60, 1586-1590. doi: 10.1212/01.WNL.0000065889.42856.F2

Mollenhauer, B., Trautmann, E., Otte, B., Ng, J., Spreer, A., Lange, P., et al. (2012). Alpha-Synuclein in human cerebrospinal fluid is principally derived from neurons of the central nervous system. J. Neural Transm. 119, 739-746. doi: 10.1007/s00702-012-0784-0

Mougenot, A. L., Nicot, S., Bencsik, A., Morignat, E., Verchére, J., Lakhdar, L., et al. (2012). Prion-like acceleration of a synucleinopathy in a transgenic mouse model. Neurobiol. Aging 33, 2225-2228. doi: 10.1016/j.neurobiolaging.2011.06.022

Mullin, S., and Schapira, A. (2013). $\alpha$-Synuclein and mitochondrial dysfunction in Parkinson's disease. Mol. Neurobiol. 47, 587-597. doi: 10.1007/s12035-0138394-x

Narayanan, N. S., Rodnitzky, R. L., and Uc, E. Y. (2013). Prefrontal dopamine signaling and cognitive symptoms of Parkinson's disease. Rev. Neurosci. 24, 267-278. doi: 10.1515/revneuro-2013-0004

Narkiewicz, J., Giachin, G., and Legname, G. (2014). In vitro aggregation assays for the characterization of alpha-synuclein prion-like properties. Prion 8, 19-32. doi: $10.4161 /$ pri.28125

Nemani, V. M., Lu, W., Berge, V., Nakamura, K., Onoa, B., Lee, M. K., et al. (2010). Increased expression of alpha-synuclein reduces neurotransmitter release by inhibiting synaptic vesicle reclustering after endocytosis. Neuron 65, 66-79. doi: 10.1016/j.neuron.2009.12.023

Oh, Y. S., Kim, H. J., Lee, K. J., Kim, Y. I., Lim, S. C., and Shon, Y. M. (2012). Cognitive improvement after long-term electrical stimulation of bilateral anterior thalamic nucleus in refractory epilepsy patients. Seizure 21, 183-187. doi: 10.1016/j.seizure.2011.12.003

Overk, C. R., and Masliah, E. (2014). Pathogenesis of synaptic degeneration in Alzheimer's disease and Lewy body disease. Biochem. Pharmacol. 88, 508-516. doi: 10.1016/j.bcp.2014.01.015

Pan-Montojo, F., Schwarz, M., Winkler, C., Arnhold, M., O’sullivan, G. A., Pal, A., et al. (2012). Environmental toxins trigger PD-like progression via increased alpha-synuclein release from enteric neurons in mice. Sci. Rep. 2:898. doi: 10.1038/srep00898

Parker, K. L., Lamichhane, D., Caetano, M. S., and Narayanan, N. S. (2013). Executive dysfunction in Parkinson's disease and timing deficits. Front. Integr. Neurosci. 7:75. doi: 10.3389/fnint.2013.00075

Plow, E. B., Pascual-Leone, A., and Machado, A. (2012). Brain stimulation in the treatment of chronic neuropathic and non-cancerous pain. J. Pain 13, 411-424. doi: 10.1016/j.jpain.2012.02.001

Recasens, A., Dehay, B., Bové, J., Carballo-Carbajal, I., Dovero, S., Pérez-Villalba, A., et al. (2014). Lewy body extracts from Parkinson disease brains trigger alpha-synuclein pathology and neurodegeneration in mice and monkeys. Ann. Neurol. 75, 351-362. doi: 10.1002/ana.24066

Rey, N. L., Petit, G. H., Bousset, L., Melki, R., and Brundin, P. (2013). Transfer of human alpha-synuclein from the olfactory bulb to interconnected brain regions in mice. Acta Neuropathol. 126, 555-573. doi: 10.1007/s00401-013-1160-3

Reyes, J. F., Rey, N. L., Bousset, L., Melki, R., Brundin, P., and Angot, E. (2014). Alpha-synuclein transfers from neurons to oligodendrocytes. Glia 62, 387-398. doi: 10.1002/glia.22611

Rezai, A. R., Machado, A. G., Deogaonkar, M., Azmi, H., Kubu, C., and Boulis, N. M. (2008). Surgery for movement disorders. Neurosurgery 62 (Suppl. 2), 809-838; discussion 838-809. doi: 10.1227/01.neu.0000316285.52865.53

Ricci, M., Guidoni, S. V., Sepe-Monti, M., Bomboi, G., Antonini, G., Blundo, C., et al. (2009). Clinical findings, functional abilities and caregiver distress in the early stage of dementia with Lewy bodies (DLB) and Alzheimer's disease (AD). Arch. Gerontol. Geriatr. 49, e101-e104. doi: 10.1016/j.archger.2008.10.001

Rochet, J. C. (2007). Novel therapeutic strategies for the treatment of protein-misfolding diseases. Expert Rev. Mol. Med. 9, 1-34. doi: 10.1017/S1462399407000385

Ruiz-Medina, J., Morgado-Bernal, I., Redolar-Ripoll, D., Aldavert-Vera, L., and Segura-Torres, P. (2008a). Intracranial self-stimulation facilitates a spatial learning and memory task in the Morris water maze. Neuroscience 154, 424-430. doi: 10.1016/j.neuroscience.2008.03.059

Ruiz-Medina, J., Redolar-Ripoll, D., Morgado-Bernal, I., Aldavert-Vera, L., and Segura-Torres, P. (2008b). Intracranial self-stimulation improves memory consolidation in rats with little training. Neurobiol. Learn. Mem. 89, 574-581. doi: 10.1016/j.nlm.2007.11.005

Sacino, A. N., Brooks, M., Mcgarvey, N. H., Mckinney, A. B., Thomas, M. A., Levites, Y., et al. (2013). Induction of CNS alpha-synuclein pathology by fibrillar and non-amyloidogenic recombinant alpha-synuclein. Acta Neuropathol. Commun. 1:38. doi: 10.1186/2051-5960-1-38

Sankar, T., Lipsman, N., and Lozano, A. M. (2014). Deep brain stimulation for disorders of memory and cognition. Neurotherapeutics 11, 527-534. doi: 10.1007/s13311-014-0275-0

Sapru, M. K., Yates, J. W., Hogan, S., Jiang, L., Halter, J., and Bohn, M. C. (2006). Silencing of human alpha-synuclein in vitro and in rat brain using lentiviral-mediated RNAi. Exp. Neurol. 198, 382-390. doi: 10.1016/j.expneurol.2005.12.024

Shah, S. A., Baker, J. L., Ryou, J. W., Purpura, K. P., and Schiff, N. D. (2009). Modulation of arousal regulation with central thalamic deep brain stimulation. Conf. Proc. IEEE Eng. Med. Biol. Soc. 2009, 3314-3317. doi: 10.1109/iembs.2009.5333751

Shirvalkar, P., Seth, M., Schiff, N. D., and Herrera, D. G. (2006). Cognitive enhancement with central thalamic electrical stimulation. Proc. Natl. Acad. Sci. U.S.A. 103, 17007-17012. doi: 10.1073/pnas.0604811103

Sibley, C. R., Seow, Y., Curtis, H., Weinberg, M. S., and Wood, M. J. (2012). Silencing of Parkinson's disease-associated genes with artificial mirtron mimics of miR-1224. Nucleic Acids Res. 40, 9863-9875. doi: 10.1093/nar/gks712

Smith, A. C., Shah, S. A., Hudson, A. E., Purpura, K. P., Victor, J. D., Brown, E. N., et al. (2009). A Bayesian statistical analysis of behavioral facilitation associated with deep brain stimulation. J. Neurosci. Methods 183, 267-276. doi: 10.1016/j.jneumeth.2009.06.028

Soriano-Mas, C., Redolar-Ripoll, D., Aldavert-Vera, L., Morgado-Bernal, I., and Segura-Torres, P. (2005). Post-training intracranial self-stimulation facilitates a hippocampus-dependent task. Behav. Brain Res. 160, 141-147. doi: 10.1016/j.bbr.2004.11.025

Soriano-Mas, C., Redolar-Ripoll, D., Guillazo-Blanch, G., Morgado-Bernal, I., and Segura-Torres, P. (2007). Intracranial self-stimulation after memory reactivation: immediate and late effects. Brain Res. Bull. 74, 51-57. doi: 10.1016/j.brainresbull.2007.05.003

Spillantini, M. G., Crowther, R. A., Jakes, R., Hasegawa, M., and Goedert, M. (1998). alpha-Synuclein in filamentous inclusions of Lewy bodies from Parkinson's disease and dementia with lewy bodies. Proc. Natl. Acad. Sci. U.S.A. 95, 6469-6473.

Stefani, A., Pierantozzi, M., Ceravolo, R., Brusa, L., Galati, S., and Stanzione, P. (2010). Deep brain stimulation of pedunculopontine tegmental nucleus (PPTg) promotes cognitive and metabolic changes: a target-specific effect or response to a low-frequency pattern of stimulation? Clin. EEG Neurosci. 41, 82-86. doi: 10.1177/155005941004100207

Stone, S. S., Teixeira, C. M., Devito, L. M., Zaslavsky, K., Josselyn, S. A., Lozano, A. M., et al. (2011). Stimulation of entorhinal cortex promotes adult neurogenesis and facilitates spatial memory. J. Neurosci. 31, 13469-13484. doi: 10.1523/JNEUROSCI.3100-11.2011

Suthana, N., Haneef, Z., Stern, J., Mukamel, R., Behnke, E., Knowlton, B., et al. (2012). Memory enhancement and deep-brain stimulation of the entorhinal area. N. Engl. J. Med. 366, 502-510. doi: 10.1056/NEJMoa1107212

Tran, H. T., Chung, C. H., Iba, M., Zhang, B., Trojanowski, J. Q., Luk, K. C., et al. (2014). Alpha-synuclein immunotherapy blocks uptake and templated propagation of misfolded alpha-synuclein and neurodegeneration. Cell Rep. 7, 2054-2065. doi: 10.1016/j.celrep.2014.05.033

Turnbull, I. M., McGeer, P. L., Beattie, L., Calne, D., and Pate, B. (1985). Stimulation of the basal nucleus of Meynert in senile dementia of Alzheimer's type. A preliminary report. Appl. Neurophysiol. 48, 216-221.

Valera, E., and Masliah, E. (2013). Immunotherapy for neurodegenerative diseases: focus on alpha-synucleinopathies. Pharmacol. Ther. 138, 311-322. doi: 10.1016/j.pharmthera.2013.01.013

Voges, J., Waerzeggers, Y., Maarouf, M., Lehrke, R., Koulousakis, A., Lenartz, D., et al. (2006). Deep-brain stimulation: long-term analysis of complications caused by hardware and surgery-experiences from a single centre. J. Neurol. Neurosurg. Psychiatr. 77, 868-872. doi: 10.1136/jnnp.2005. 081232

Volpicelli-Daley, L. A., Luk, K. C., Patel, T. P., Tanik, S. A., Riddle, D. M., Stieber, A., et al. (2011). Exogenous alpha-synuclein fibrils induce Lewy body pathology 
leading to synaptic dysfunction and neuron death. Neuron $72,57-71$. doi: 10.1016/j.neuron.2011.08.033

Wagner, J., Ryazanov, S., Leonov, A., Levin, J., Shi, S., Schmidt, F., et al. (2013). Anle138b: a novel oligomer modulator for disease-modifying therapy of neurodegenerative diseases such as prion and Parkinson's disease. Acta Neuropathol. 125, 795-813. doi: 10.1007/s00401-013-1114-9

Watts, J. C., Giles, K., Oehler, A., Middleton, L., Dexter, D. T., Gentleman, S. M., et al. (2013). Transmission of multiple system atrophy prions to transgenic mice. Proc. Natl. Acad. Sci. U.S.A. 110, 19555-19560. doi: $10.1073 /$ pnas. 1318268110

Williams, Z. M., and Eskandar, E. N. (2006). Selective enhancement of associative learning by microstimulation of the anterior caudate. Nat. Neurosci. 9, 562-568. doi: $10.1038 / \mathrm{nn} 1662$

Wood, S. J., Wypych, J., Steavenson, S., Louis, J. C., Citron, M., and Biere, A. L. (1999). alpha-synuclein fibrillogenesis is nucleation-dependent. Implications for the pathogenesis of Parkinson's disease. J. Biol. Chem. 274, 19509-19512.

Yuan, B., and Sierks, M. R. (2009). Intracellular targeting and clearance of oligomeric alpha-synuclein alleviates toxicity in mammalian cells. Neurosci. Lett. 459, 16-18. doi: 10.1016/j.neulet.2009.04.046

Zaltieri, M., Longhena, F., Pizzi, M., Missale, C., Spano, P., and Bellucci, A. (2015). Mitochondrial dysfunction and alpha-synuclein synaptic pathology in Parkinson's Disease: who's on first? Parkinsons. Dis. 2015:108029. doi: $10.1155 / 2015 / 108029$

Zhou, C., Emadi, S., Sierks, M. R., and Messer, A. (2004). A human single-chain Fv intrabody blocks aberrant cellular effects of overexpressed alpha-synuclein. Mol. Ther. 10, 1023-1031. doi: 10.1016/j.ymthe.2004.08.019

Zhou, W., Bercury, K., Cummiskey, J., Luong, N., Lebin, J., and Freed, C. R. (2011). Phenylbutyrate up-regulates the DJ-1 protein and protects neurons in cell culture and in animal models of Parkinson disease. J. Biol. Chem. 286, 14941-14951. doi: 10.1074/jbc.M110. 211029

Conflict of Interest Statement: The authors declare that the research was conducted in the absence of any commercial or financial relationships that could be construed as a potential conflict of interest.

Copyright (ㅇ 2015 Zhang, Kim and Narayanan. This is an open-access article distributed under the terms of the Creative Commons Attribution License (CC BY). The use, distribution or reproduction in other forums is permitted, provided the original author(s) or licensor are credited and that the original publication in this journal is cited, in accordance with accepted academic practice. No use, distribution or reproduction is permitted which does not comply with these terms. 